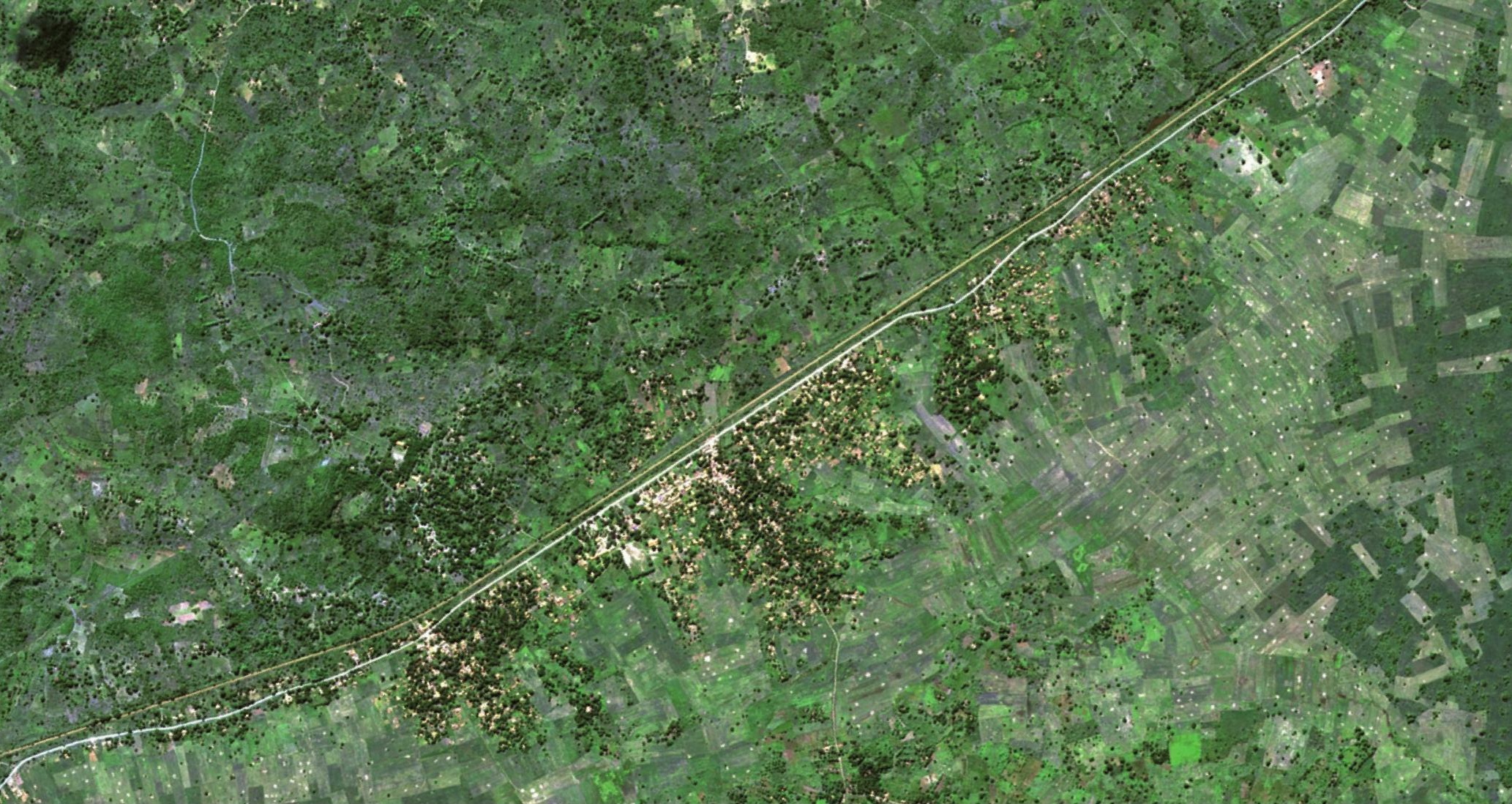

WorldView-2 satellite maps have helped the Tropical Ecology, Assessment and Monitoring Network to operate on a far larger scale.

\title{
Conservation science outside the comfort zone
}

\author{
Researchers like to work on projects that start small and slowly scale up. They must \\ think bigger and faster, says Sandy J. Andelman, to tackle today's problems in time.
}

S ix years ago, I leapt from the ivory tower. I left my comfortable job as deputy director of the National Center for Ecological Analysis and Synthesis at the University of California, Santa Barbara, to do something big and risky: to lead the creation of the Tropical Ecology, Assessment and Monitoring (TEAM) Network, an early warning system for biodiversity loss caused by climate change. The opportunity to work at a global scale with long-term funding prompted my leap. The project was in principle supported for 10 years by US $\$ 43$ million from the Gordon and Betty Moore Foundation of Palo Alto, California.

Today, TEAM (www.teamnetwork.org) links 18 tropical monitoring sites in 15 countries in Africa, Asia and Latin America, and continues to grow. At each site, local partners use standardized methods to measure five things: the diversity of trees and woody vines called lianas; carbon stocks; bird and mammal diversity; humanlandscape interactions; and climate. All of the data are freely available in near real time. The project is led by Conservation
International (CI) in Arlington, Virginia.

At the beginning, I thought that the best strategy was to set up sites one by one, measuring many things at each site to fully capture local complexity. It soon became clear that adding sites incrementally would not answer our global questions. We needed to sacrifice some local details to get the global system up and running quickly. A new opportunity really brought that message home. In 2009, we gained a boost of funding to monitor ecosystem services. It came with strings attached: there was no time to start small, we needed to start big.

\section{BIGGER IS BETTER}

Initially I fought against getting too big too fast. But I have had a change of heart. I now believe that all conservation scientists need to be thinking and acting more boldly than we are today. If we are to deliver the knowledge we need to manage our hot, crowded, rapidly changing Earth, we need to get outside our comfort zones and take some large, if uncomfortable, steps.
In November 2009, TEAM secured a grant from the Bill and Melinda Gates Foundation in Seattle, Washington, initially for $\$ 435,000$, to lead the development and field testing of a set of standard metrics for ecosystem services in areas of agricultural intensification. We had a perfect place for the pilot. TEAM had a well-managed monitoring site in the Udzungwa Mountains National Park in Tanzania. To its south, the Kilombero Valley was targeted by the Tanzanian Ministry of Agriculture and international donors for around $\$ 65$ million in investments to double food production over a three-year period. The farmers there depend directly on ecosystem services from the Udzungwa Forest - including water, wood for fuel, bush meat and protection from erosion - for their agricultural production and livelihoods.

For the pilot, we planned to monitor the following in both the Udzungwa and the Kilombero Valley: biophysical properties (from biodiversity to water quality and climate); agricultural productivity (for example, areas planted and crop yield); livelihood measures 
(such as household income and under-five mortality rates); and resilience of natural and human systems to climate variability.

Many ecological projects tackle only a few hectares. TEAM sites average about 3,800 square kilometres, with standardized field measurements covering around $400 \mathrm{~km}^{2}$. The pilot area was a daunting $5,000 \mathrm{~km}^{2}$.

Two months after receiving the grant, Prabhu Pingali, deputy director of agricultural development at the Gates Foundation, told me that our envisioned pilot project was far too small and slow. The foundation needed a pilot that, within a year, would cover much of southern Tanzania - a seemingly impossible area of about $335,000 \mathrm{~km}^{2}$.

\section{WEIGHING THE TRADE-OFFS}

Pingali's rationale was compelling. There have never been as many hungry people on the planet as there are today, most of them smallholder farmers in developing countries. Conservation scientists need to provide good data and methods for monitoring

change, at relevant scales, as soon $\sum_{\breve{H}}^{x}$ as possible. Otherwise, decisions about agricultural development is will continue to be made without properly weighing the trade-offs and synergies between agriculture, nature and human livelihoods. The Alliance for a Green Revolution in Africa (AGRA), a Gates Foundation partner, aims to double food production in three years in southern Tanzania and in regions of Mozambique, Ghana and Mali. It needed good baseline data and monitoring techniques for ecosystem services immediately - not in a few years. Pingali told me: we can give you more resources, but we can't give you more time.

This was a troubling challenge. I was comfortable with the model of: start small because resources are scarce; carefully test methods and sampling design; publish initial results; and then iterate and scale upwards slowly and carefully, with peer review informing every step. I explained to Pingali that 'we' - Conservation International, the TEAM Network, the conservation-science community and I - had no idea how to monitor ecosystem services consistently at such a huge scale. But I took another leap and said we would try.

Eighteen months later, we have completed the pilot project. Thinking about large-scale methods from the outset pushed us towards practical, innovative technologies and partnerships.

For example, we used high-resolution imagery from the WorldView-2 satellite to assess fine-scale land-cover patterns, from tilled land to forest. These kinds of data are expensive, but they are needed for large-scale work. We distributed georeferencing camera phones to local people and researchers. We used their photos to validate and supplement remote-sensing images. We partnered with the Tanzanian National Bureau of Statistics and the World Bank (which together run a gold-standard annual survey of livelihood and agricultural management) to integrate their social data with our biophysical measures - of water availability, for example. And we adopted a protocol for measuring soil organic-carbon levels from the African Soil Information Service and the World Agroforestry Centre in Nairobi, rather than reinventing the wheel. We are now replicating this strategy in Rwanda and plans are under way to cover the rest of sub-Saharan Africa, Asia and Latin America.

There have been bumps in the road. We still don't have the right algorithms to automate processing of the high-resolution, remote-sensing images, for example. It takes one highly skilled analyst two weeks

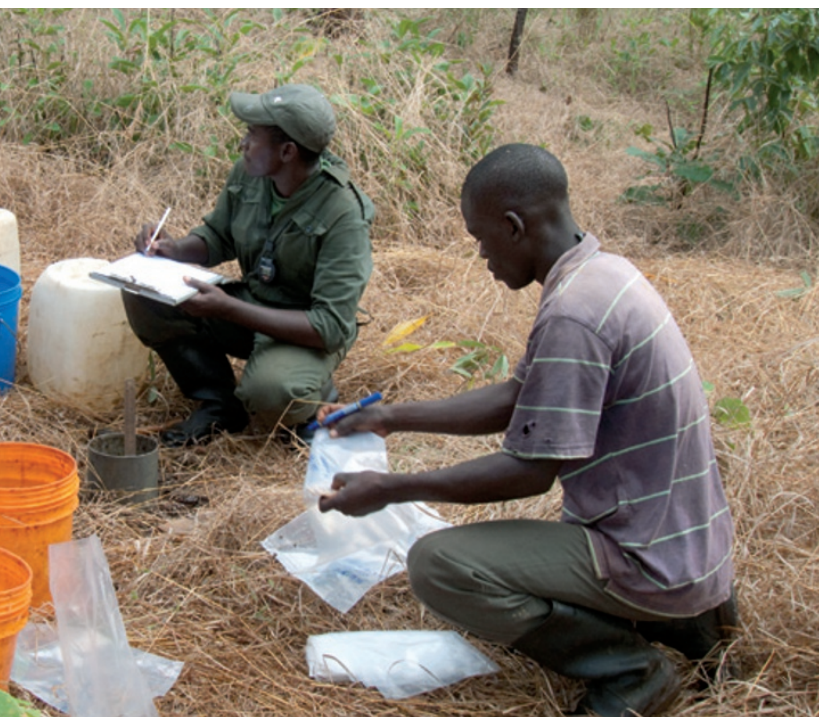

pilot project in Tanzania using highly targeted on-the-ground sampling.

pace of the peer-review process and the outdated reward systems of our institutions. But these are obstacles that we must overcome.

Detractors may argue that large-scale approaches by definition can't capture the level of detail needed to fully understand complex systems. But development decisions are large and often can't handle that level of complexity. The key is to select the measures

"Weare that are relevant to both
informing battles, but not winning the war." science and policy.

I am not saying that conservation researchers should give up scientific and analytical rigour. But we do need to trade in our slow, incremental models of funding and investigation for something bolder. In 2010, the entire Division of Environmental Biology at the US National Science Foundation gave out 702 grants, averaging just over $\$ 212,000$ each, with an average duration of two years. Forty-nine per cent of these went to lone investigators. Planning for the US National Ecological Observatory Network (NEON) began 11 years ago, and has cost more than $\$ 90$ million to date. But this comes from a pot of money devoted to construction of large facilities, not to ongoing research, and it has not yet moved to implementation.

The NSF funding model does not support global-scale conservation science for a rapidly changing world. We need to look to non-traditional funding sources such as the private sector, and actively work to set up consortia of donors.

What will it cost to scale up? One 2008 estimate suggested that a global monitoring network for biodiversity and ecosystem services would cost \$309 million to \$772 million a year (R. J. Scholes et al. Science 321, 1044-1045; 2008). On the basis of my experience, I believe that we can

to process an image covering $100 \mathrm{~km}^{2}$. But on the whole it worked. We established, very quickly, a baseline measure of the system before agricultural intensification.

\section{BIG AMBITIONS}

Most conservation science today isn't ambitious enough. We are informing battles, but we are not providing the knowledge needed, at the scale needed, to win the war. For example, global policy-makers and national governments are trying to produce robust estimates of forest carbon stocks to assist in managing emissions and carbon sequestration. But the error in regional- and global-scale estimates of forest carbon is as high as $50 \%$, mainly because of limitations in the scale of measurements. There are some obvious constraints: limited funding, the slow create a scientifically credible, policy-relevant global network for more like \$10 million a year, by integrating proven methods from successful networks - such as TEAM, NEON and the Digital Soil Map of the World - with the full arsenal of innovative informatics tools and mobile technologies. Such a network will not measure everything, everywhere, but it should be able to provide the targeted data that policy-makers need. It is time for conservation scientists and donors to step up to this challenge.

Sandy Andelman is vice-president and director of the Tropical Ecology, Assessment and Monitoring (TEAM) Network, with Conservation International, Arlington, Virginia 22202, USA.

e-mail:s.andelman@conservation.org 